\title{
Effectiveness of a Low-Calorie Weight Loss Program in Moderately and Severely Obese Patients
}

\author{
Julia K. Winkler ${ }^{a} \quad J o b s t-H e n d r i k$ Schultz ${ }^{b}$ Annika Woehning ${ }^{a}$ David Piel $^{a}$ \\ Lena Gartner $^{a} \quad$ Mirjam Hildebrand $^{a} \quad$ Eva Roeder ${ }^{c}$ Peter P. Nawroth ${ }^{a}$ \\ Christian Wolfrum ${ }^{c}$ Gottfried Rudofsky ${ }^{a}$ \\ ${ }^{a}$ Department of Medicine I and Clinical Chemistry, ${ }^{b}$ Department of General Internal \\ Medicine and Psychosomatics, University of Heidelberg, Heidelberg, Germany, 'Swiss \\ Federal Institute of Technology, Institute of Food Nutrition and Health, ETH Zürich, SLA C94, \\ Schwerzenbach, Switzerland
}

\author{
Key Words \\ Weight loss · Weight maintenance · Weight regain - Obesity · Low calorie diet · Formula diet . \\ Diabetes conversion
}

\begin{abstract}
Aims: To compare effectiveness of a 1-year weight loss program in moderately and severely obese patients. Methods: The study sample included 311 obese patients participating in a weight loss program, which comprised a 12-week weight reduction phase (low-calorie formula diet) and a 40-week weight maintenance phase. Body weight and glucose and lipid values were determined at the beginning of the program as well as after the weight reduction and the weight maintenance phase. Participants were analyzed according to their BMI class at baseline $\left(30-34.9 \mathrm{~kg} / \mathrm{m}^{2} ; 35-39.9 \mathrm{~kg} / \mathrm{m}^{2} ; 40-44.9 \mathrm{~kg} / \mathrm{m}^{2} ; 45-49.9 \mathrm{~kg} / \mathrm{m}^{2} ; \geq 50 \mathrm{~kg} / \mathrm{m}^{2}\right)$. Furthermore, moderately obese patients (BMI $<40 \mathrm{~kg} / \mathrm{m}^{2}$ ) were compared to severely obese participants (BMI $\geq 40 \mathrm{~kg} / \mathrm{m}^{2}$ ). Results: Out of 311 participants, 217 individuals completed the program. Their mean baseline BMI was $41.8 \pm 0.5 \mathrm{~kg} / \mathrm{m}^{2}$. Average weight loss was $17.9 \pm 0.6 \%$, resulting in a BMI of $34.3 \pm 0.4 \mathrm{~kg} / \mathrm{m}^{2}$ after 1 year $(p<0.001)$. Overall weight loss was not significantly different in moderately and severely obese participants. Yet, severely obese participants achieved greater weight loss during the weight maintenance phase than moderately obese participants $(-3.1 \pm 0.7 \%$ vs. $-1.2 \pm 0.6 \%$; $p=0.04)$. Improvements in lipid profiles and glucose metabolism were found throughout all BMI classes. Conclusion: 1-year weight loss intervention improves body weight as well as lipid and glucose metabolism not only in moderately, but also in severely obese individuals.

(c) 2013 S. Karger GmbH, Freiburg
\end{abstract}

J.K. Winkler and J.-H. Schultz contributed equally to this work. 
Winkler et al.: Effectiveness of a Low-Calorie Weight Loss Program in Moderately and Severely Obese Patients

\section{Introduction}

Obesity has become a worldwide epidemic and a serious global health issue [1-3]. According to the World Health Organization (WHO), obesity more than doubled worldwide since 1980 [4]. In 2008, 1.5 billion adults were overweight [4]. Of these, nearly 300 million women and more than 200 million men were obese [4]. In the past years, the prevalence of obesity, especially severe obesity (BMI $\geq 40 \mathrm{~kg} / \mathrm{m}^{2}$ ), has increased [5]. Severe obesity is frequently accompanied by various obesity-related health issues, e.g. type 2 diabetes, cardiovascular diseases, osteoarthritis and certain types of cancer, and therefore associated with a reduced life expectancy $[3,4,6]$. Hence, promising obesity treatment approaches aiming at body weight reduction and improvement of cardiovascular risk factors such as hyperglycemia and hyperlipidemia are required. However, most commercial weight loss interventions remain unsatisfactory [7]. Particularly in severe obesity, medical treatment approaches are believed to be disappointing [8]. Thus, severely obese patients are often referred to bariatric surgery $[9,10]$. Multimodal medically supervised weight loss programs have been suggested as possible treatment option for obesity and obesity-related diseases [11]. So far, the efficacy of such programs in severely obese patients has not been studied extensively. Therefore, our study aimed at comparing weight loss and improvement of cardiovascular risk factors in severely obese (BMI $\left.\geq 40 \mathrm{~kg} / \mathrm{m}^{2}\right)$ and moderately obese subjects (BMI $<40 \mathrm{~kg} / \mathrm{m}^{2}$ ) during a 1 -year medically supervised low-calorie weight loss program (OPTIFAST ${ }^{\circledR} 52$ ).

\section{Material and Methods}

\section{The Weight Loss Program OPTIFAST ${ }^{\circledR} 52$}

The present study was a single-center, longitudinal investigation including obese participants of the multidisciplinary, non-surgical weight loss program OPTIFAST ${ }^{\circledR} 52$ (franchise holder Nestlé Inc., Vevey, Switzerland). It was established in Germany in 1999 to treat obese individuals of at least 18 years of age and a minimum BMI of $30 \mathrm{~kg} / \mathrm{m}^{2}$. Patients with different states of glucose intolerance are included. Patients suffering from an eating disorder may not participate in the program. There were no further inclusion or exclusion criteria.

OPTIFAST ${ }^{\circledR} 52$ is a 1 -year lifestyle modification program including five different phases and four modules (psychology, medicine, dietetics and exercise). It is implemented by qualified health professionals including psychologists, physicians, nutritionists, and physical therapists [11]. During the program, closed groups of 8-15 persons meet weekly for about $3.5 \mathrm{~h}$ per session. The five phases include a 1-week introduction and a 12-week period of low-calorie diet (LCD, Optifast 800 formula, Nestlé Inc.; $800 \mathrm{kcal} /$ day with $70 \mathrm{~g}$ protein, $15 \mathrm{~g}$ fat and $100 \mathrm{~g}$ carbohydrates). During this time, participants consume five packages of formula diet per day ( $160 \mathrm{kcal}$ each, dissolved in $300 \mathrm{ml}$ water). This phase is accompanied by 12 medical examinations, 12 exercise units, 2 behavior therapy lessons, and 2 nutrition counselings. In the analysis presented here, these two phases are referred to as weight reduction phase $\left(T_{0}-T_{1}\right)$ since in this period the most pronounced weight loss occurs. It is followed by a 6-week refeeding phase in which solid food is reintroduced and stepwise replaces formula diet without change of total calorie intake. This phase is accompanied by 6 medical examinations, 6 exercise units, 2 behavior therapy lessons, and 6 nutrition counselings. Subsequently, a 7-week stabilization phase follows in which energy intake is stepwise enhanced to an individual level. The steps are predefined according to the program instructions: Step 1 accounts for approximately 1,200 kcal/day, step 2 for 1,400 kcal/day, step 3 for 1,600 kcal/day, step 4 for 1,800 kcal/day, and step 5 for 2,000 kca/day. Determination of the individual level is based on current weight, daily physical activity, and the further goals of each participant. Dietary intake is controlled by a point-based system. Points refer to protein, carbohydrate and fat content of the consumed food. This stabilization phase is accompanied by 3 medical examinations, 4 exercise units, 4 behavior therapy lessons, and 3 nutrition counselings. A 26-week maintenance phase follows, in which nutritional education and behavior modification is intensified to acquire strategies to cope with e.g. stress or frustration and to establish new reward strategies in order to achieve long-term weight control. Again, it is accompanied by 6 medical examinations, 13 exercise units, 22 behavior therapy lessons, and 5 nutrition counselings. In the current analysis the refeeding, stabilization and maintenance phases are summarized as weight maintenance phase $\left(\mathrm{T}_{1}-\mathrm{T}_{2}\right)$. 
Winkler et al.: Effectiveness of a Low-Calorie Weight Loss Program in Moderately and Severely Obese Patients

Altogether, treatment during the program is similar throughout all BMI categories. In this study, data was included from the beginning of the program $\left(\mathrm{T}_{0}\right)$, from week 12 after the weight reduction phase $\left(\mathrm{T}_{1}\right)$, and from week 52 after the weight maintenance phase $\left(\mathrm{T}_{2}\right)$.

\section{Study Collective}

The ethics committee at the University of Heidelberg approved the study, and all participants gave written informed consent. The study sample included 311 obese individuals participating in the weight loss program at the Obesity Center of the University Hospital of Heidelberg between 2004 and 2011. Participants were grouped according to their baseline BMI $\left(30.0-34.9 \mathrm{~kg} / \mathrm{m}^{2} ; 35.0-39.9 \mathrm{~kg} / \mathrm{m}^{2} ; 40.0-44.9 \mathrm{~kg} / \mathrm{m}^{2} ; 45.0-\right.$ $49.9 \mathrm{~kg} / \mathrm{m}^{2} ; \geq 50.0 \mathrm{~kg} / \mathrm{m}^{2}$ ). Participants with an initial BMI of $30.0-39.9 \mathrm{~kg} / \mathrm{m}^{2}$ were classified as moderately obese and compared to the group of severely obese participants (BMI $\geq 40.0 \mathrm{~kg} / \mathrm{m}^{2}$ ), which included super obese subjects with a BMI $\geq 50.0 \mathrm{~kg} / \mathrm{m}^{2}$. At the end of the program, subjects with a BMI of $25.0-29.9 \mathrm{~kg} / \mathrm{m}^{2}$ were classified as overweight and subjects with a BMI $<25.0 \mathrm{~kg} / \mathrm{m}^{2}$ as normal-weight.

Of the 311 participants, 47 suffered from overt diabetes at baseline. Out of these patients, 13 were treated with dietary intervention, 27 were treated with oral antidiabetic drugs, and 7 patients received a basal or intensified insulin therapy.

\section{Anthropometric and Laboratory Measurements}

During the 1-year program, body weight was monitored weekly on a calibrated scale (Seca 764, Hamburg, Germany) after an 8-hour fast. BMI was calculated as weight (kg) divided by the square of the height (m). Moreover, systolic and diastolic blood pressure was assessed regularly. Blood samples were taken three times during the program each after a fasting time of at least $8 \mathrm{~h}$. Parameters from the beginning $\left(\mathrm{T}_{0}\right)$ and the end of the 1-year program $\left(\mathrm{T}_{2}\right)$ were included in the analysis. Concentrations of blood glucose, total cholesterol, low-density lipoprotein (LDL) cholesterol, high-density lipoprotein (HDL) cholesterol, and triglycerides were measured in the central laboratory of the University Hospital of Heidelberg. Glucose levels were assessed from blood collection tubes containing sodium fluoride and lipid parameters were measured from lithium heparin tubes. Separated plasma was analyzed on a Siemens ADVIA ${ }^{\circledR} 2400$ chemistry analyzer. Siemens test kits were used according to the manufacturer's instruction to measure the concentrations of glucose, total cholesterol, HDL cholesterol, and triglycerides. Moreover, the Friedewald equation was applied to assess the concentration of LDL cholesterol.

\section{Diagnosis of Impaired Glucose Metabolism and Diabetes}

Diagnosis of type 2 diabetes was based on the fasting glucose levels and the results of an oral glucose tolerance test (OGTT), which was introduced in the OPTIFAST ${ }^{\circledR} 52$ program in 2006. Impaired fasting glucose (IFG, fasting glucose levels: 110-125 mg/dl), impaired glucose tolerance (IGT, glucose levels in 2-hour OGTT: $140-199 \mathrm{mg} / \mathrm{dl}$ ) and type 2 diabetes (fasting glucose levels $\geq 126 \mathrm{mg} / \mathrm{dl}$, glucose levels in 2-hour OGTT $\geq$ $200 \mathrm{mg} / \mathrm{dl}$ ) were defined according to the WHO criteria [12]. HOMA (homeostasis model assessment) index was calculated as: Insulin $(\mu \mathrm{U} / \mathrm{ml}) \times$ glucose $(\mathrm{mmol} / \mathrm{l}) / 22.5$.

\section{Statistical Analysis}

A per-protocol analysis including only subjects who completed the whole program was chosen to study the efficacy of the OPTIFAST ${ }^{\circledR} 52$ program on weight reduction, lipid improvement, and diabetes remission. Data analysis was performed with Microsoft Excel Version 2007 and SPSS Version 18.0. Variables are depicted as means \pm standard error of the mean (SEM) or percentages. Statistical significance was calculated with a two-sided t-test and chi-square $\left(\chi^{2}\right)$ test. Furthermore, a multiple regression analysis was conducted with covariates (gender, age (years), diabetes, hypertension, BMI at $\mathrm{T}_{0}\left(\mathrm{~kg} / \mathrm{m}^{2}\right)$ ) for adjustment of potential confounding. A $p$ value $<0.05$ was assumed to be statistically significant.

\section{Results}

The 1-year weight loss program was completed by 217 of the 311 participants while 94 terminated prematurely, which corresponds to an attrition rate of $30.2 \%$. The attrition rate was nearly similar for moderately $(28.3 \%)$ and severely obese patients $(31.5 \% ; \mathrm{p}=0.58)$. Baseline characteristics of the completers are summarized in table 1. Furthermore, table 2 
Winkler et al.: Effectiveness of a Low-Calorie Weight Loss Program in Moderately and Severely Obese Patients

Table 1. Baseline characteristics are depicted for all completers $(n=217)$ and according to their initial BMI class ${ }^{\mathrm{a}}$

All

BMI, $\mathrm{kg} / \mathrm{m}^{2}$

$30-34.9 \quad 35-39.9 \quad 40-44.9 \quad 45-49.9 \quad$ BMI $\geq 50$

Total

Age, years

$44.7 \pm 0.8$

$142 / 75$

$1.71 \pm 0.01$

Height, $m$

Weight, $\mathrm{kg}$

$\mathrm{BMI}, \mathrm{kg} / \mathrm{m}^{2}$

Total cholesterol, $\mathrm{mg} / \mathrm{dl}$

LDL cholesterol, $\mathrm{mg} / \mathrm{dl}$

HDL cholesterol, mg/dl

Triacylglycerols, mg/dl

Glucose, mg/dl

HOMA-IR

Systolic blood pressure, $\mathrm{mm} \mathrm{Hg}$

Diastolic blood pressure $\mathrm{mm} \mathrm{Hg}$

Lipid lowering agents, \%

Antidiabetic agents, \%

Antihypertensive medication, \%

Antipsychotic drugs, \%
$122.8 \pm 1.6$

$41.8 \pm 0.5$

$201 \pm 3$

$122 \pm 2$

$50 \pm 1$

$145 \pm 6$

$107 \pm 2$

$7.1 \pm 0.6$

$140 \pm 1$

$89 \pm 1$

9.3

17.2

43.8

11.5

$\begin{array}{ll}45.8 \pm 2.0 & 45.9 \pm 1.4 \\ 22 / 9 & 44 / 27 \\ 1.71 \pm 0.02 & 1.72 \pm 0.01 \\ 97.3 \pm 2.1 & 111.9 \pm 1.4 \\ 33.3 \pm 0.2 & 37.6 \pm 0.2 \\ 221 \pm 8 & 202 \pm 5 \\ 134 \pm 8 & 123 \pm 4 \\ 53 \pm 2 & 51 \pm 2 \\ 163 \pm 19 & 143 \pm 10 \\ 99 \pm 3 & 105 \pm 3 \\ 4.9 \pm 0.9 & 5.3 \pm 0.4 \\ 135 \pm 3 & 139 \pm 2 \\ 87 \pm 2 & 89 \pm 1 \\ 16.1 & 9.9 \\ 4.2 & 15.9 \\ 25.8 & 38.0 \\ 6.5 & 12.7\end{array}$

$44.3 \pm 1.7$

$37 / 15$

$1.70 \pm 0.01$

$124.1 \pm 2.0$

$42.6 \pm 0.2$

$202 \pm 5$

$123 \pm 5$

$49 \pm 1$

$151 \pm 11$

$110 \pm 5$

$8.4 \pm 1.9$

$140 \pm 3$

$89 \pm 2$

7.7

17.4

42.3

9.6
$43.4 \pm 1.9$

$29 / 10$

$1.70 \pm 0.01$

$136.5 \pm 2.2$

$47.1 \pm 0.2$

$196 \pm 5$

$117 \pm 4$

$52 \pm 2$

$135 \pm 11$

$106 \pm 4$

$9.1 \pm 2.3$

$142 \pm 2$

$89 \pm 2$

5.3

21.6

61.5

17.9
$42.5 \pm 1.8$

$10 / 14$

$1.72 \pm 0.02$

$162.7 \pm 5.8$

$54.5 \pm 1.1$

$174 \pm 7$

$107 \pm 6$

$42 \pm 2$

$129 \pm 7$

$115 \pm 8$

$9.1 \pm 1.3$

$142 \pm 4$

$88 \pm 2$

8.3

27.3

58.3

8.3

\section{Men}

Age, years

Height, $m$

Weight, kg

BMI, $\mathrm{kg} / \mathrm{m}^{2}$

Total cholesterol, $\mathrm{mg} / \mathrm{dl}$

LDL cholesterol, $\mathrm{mg} / \mathrm{dl}$

HDL cholesterol, mg/dl

Triacylglycerols, mg/dl

Glucose, mg/dl

HOMA-IR

$45.9 \pm 1.4$
$1.79 \pm 0.01$
$136.5 \pm 3.1$
$42.7 \pm 0.9$
$203 \pm 5$
$121 \pm 4$
$45 \pm 1$
$184 \pm 12$
$113 \pm 5$
$7.8 \pm 0.9$
$144 \pm 2$
$90 \pm 1$
16.0
22.4
46.7
9.3

$\begin{array}{ll}48.0 \pm 3.1 & 47.4 \pm 2.7 \\ 1.79 \pm 0.03 & 1.80 \pm 0.02 \\ 107.6 \pm 3.5 & 121.1 \pm 2.4 \\ 33.6 \pm 0.3 & 37.4 \pm 0.3 \\ 236 \pm 14 & 207 \pm 8 \\ 129 \pm 17 & 123 \pm 6 \\ 44 \pm 2 & 48 \pm 2 \\ 285 \pm 41 & 178 \pm 23 \\ 101 \pm 5 & 113 \pm 8 \\ 8.3 \pm 2.5 & 6.0 \pm 0.6 \\ 137 \pm 5 & 143 \pm 3 \\ 85 \pm 3 & 92 \pm 2 \\ 11.1 & 18.5 \\ 0 & 32 \\ 0 & 44.4 \\ 0 & 14.8\end{array}$

$44.6 \pm 2.9$

$42.1 \pm 4.2$

$45.8 \pm 1.8$

$1.80 \pm 0.01 \quad 1.79 \pm 0.03$

$139.7 \pm 1.9 \quad 149.8 \pm 4.6$

$43.1 \pm 0.3$

$149.8 \pm 4.6$

$209 \pm 12$

$129 \pm 11$

$43 \pm 2$

$192 \pm 28$

$124 \pm 14$

$6.2 \pm 1.6$

$146 \pm 5$

$89 \pm 3$

20

14.3

53.3

6.7

$197 \pm 10$

$112 \pm 10$

$46 \pm 5$

$186 \pm 29$

$105 \pm 7$

$12.3 \pm 4.6$

$150 \pm 4$

$91 \pm 4$

10

30

60

10

$1.75 \pm 0.03$

$171.6 \pm 8.6$

$55.3 \pm 1.6$

$175 \pm 9$

$110 \pm 7.3$

$41 \pm 2$

$126 \pm 9$

$113 \pm 13$

$9.2 \pm 1.7$

$142 \pm 6$

$89 \pm 3$

14.3

16.7

64.3

7.1

\section{Women}

Age, years

Height, m

Weight, kg

BMI, $\mathrm{kg} / \mathrm{m}^{2}$

Total cholesterol, mg/dl

LDL cholesterol, mg/dl

HDL cholesterol, mg/dl

Triacylglycerols, mg/dl

Glucose, mg/dl

HOMA-IR

Systolic blood pressure, $\mathrm{mm} \mathrm{Hg}$

Diastolic blood pressure $\mathrm{mm} \mathrm{Hg}$

Lipid lowering agents, \%

Antidiabetic agents, \%

Antihypertensive medication, \%

Antipsychotic drugs, \%

$\begin{array}{lll}44.0 \pm 1.0 & 44.9 \pm 2.6 & 45.0 \pm 1.6 \\ 1.67 \pm 0.01 & 1.67 \pm 0.02 & 1.68 \pm 0.01 \\ 115.6 \pm 1.6 & 93.1 \pm 2.1 & 106.3 \pm 1.2 \\ 41.3 \pm 0.5 & 33.2 \pm 0.3 & 37.7 \pm 0.2 \\ 199 \pm 3 & 214 \pm 10 & 199 \pm 6 \\ 122 \pm 3 & 135 \pm 10 & 123 \pm 4 \\ 53 \pm 1 & 56 \pm 3 & 53 \pm 2 \\ 125 \pm 4 & 119 \pm 11 & 121 \pm 8 \\ 103 \pm 2 & 99 \pm 4 & 100 \pm 3 \\ 6.7 \pm 0.9 & 3.9 \pm 0.6 & 4.9 \pm 0.5 \\ 137 \pm 1 & 134 \pm 3 & 136 \pm 3 \\ 88 \pm 1 & 88 \pm 2 & 87 \pm 2 \\ 5.7 & 18.2 & 4.5 \\ 14.4 & 5.6 & 5.3 \\ 42.3 & 36.4 & 34.1 \\ 12.7 & 9.1 & 11.4\end{array}$

$44.1 \pm 2.1$

$1.67 \pm 0.01$

$117.7 \pm 1.8$

$42.4 \pm 0.2$

$200 \pm 6$

$121 \pm 6$

$51 \pm 2$

$134 \pm 9$

$104 \pm 4$

$9.3 \pm 2.5$

$138 \pm 3$

$89 \pm 2$

2.7

18.8

37.8

10.8

$43.8 \pm 2.1$
$1.67 \pm 0.01$
$132.0 \pm 1.9$
$47.2 \pm 0.2$
$196 \pm 6$
$118 \pm 4$
$54 \pm 2$
$119 \pm 10$
$106 \pm 5$
$7.7 \pm 2.7$
$139 \pm 3$
$88 \pm 2$
3.6
18.5
62.1
20.7

$37.8 \pm 3.1$

$1.68 \pm 0.02$

$150.1 \pm 5.6$

$53.3 \pm 1.3$

$173 \pm 14$

$103 \pm 11$

$43 \pm 3$

$134 \pm 12$

$117 \pm 5$

$9.0 \pm 2.1$

$141 \pm 6$

$87 \pm 3$

0

40

50

10

$\mathrm{F}=$ Female; $\mathrm{M}=$ male. ${ }^{\mathrm{a}}$ Mean values $\pm \mathrm{SEM}$ are given . 
Winkler et al.: Effectiveness of a Low-Calorie Weight Loss Program in Moderately and Severely Obese Patients

Table 2. Baseline characteristics are depicted for the completers of the program with a BMI $<40 \mathrm{~kg} / \mathrm{m}^{2}$ and those with a BMI $\geq 40 \mathrm{~kg} / \mathrm{m}^{2}$ a

\begin{tabular}{llll}
\hline & \multicolumn{2}{l}{ BMI, kg/m $\mathrm{m}^{2}$} & \\
\cline { 2 - 4 } & $<40$ & $\geq 40$ & $<40$ vs. $\geq 40$ \\
\hline Age, years & $45.9 \pm 1.2$ & $43.6 \pm 1.1$ & $0.15^{*}$ \\
Sex F/M, $\mathrm{l}$ & $66 / 36$ & $76 / 39$ & $0.83^{\dagger}$ \\
Height, m & $1,72 \pm 0.01$ & $1.71 \pm 0.01$ & $0.30^{*}$ \\
Weight, kg & $107.5 \pm 1.4$ & $136.3 \pm 2.2$ & $0.000^{*}$ \\
BMI, kg/m & $36.3 \pm 0.2$ & $46.6 \pm 0.5$ & $0.000^{*}$ \\
Total cholesterol, mg/dl & $208 \pm 4$ & $195 \pm 3$ & $0.02^{*}$ \\
LDL cholesterol, mg/dl & $126 \pm 4$ & $118 \pm 3$ & $0.06^{*}$ \\
HDL cholesterol, mg/dl & $52 \pm 1$ & $48 \pm 1$ & $0.04^{*}$ \\
Triacylglycerols, mg/dl & $149 \pm 9$ & $141 \pm 6$ & $0.48^{*}$ \\
Glucose, mg/dl & $103 \pm 2$ & $109 \pm 3$ & $0.12^{*}$ \\
HOMA-IR & $5.2 \pm 0.4$ & $8.8 \pm 1.1$ & $0.007^{*}$ \\
Systolic blood pressure, mm Hg & $138 \pm 2$ & $141 \pm 2$ & $0.15^{*}$ \\
Diastolic blood pressure, mm Hg & $88 \pm 1$ & $89 \pm 1$ & $0.76^{*}$ \\
Lipid lowering agents, \% & 11.8 & 7.0 & $0.23^{\dagger}$ \\
Antidiabetic agents, \% & 12.6 & 21.0 & $0.13^{\dagger}$ \\
Antihypertensive medication, \% & 34.3 & 52.2 & $0.008^{\dagger}$ \\
Antipsychotic drugs, \% & 10.8 & 12.2 & $0.75^{\dagger}$ \\
\hline
\end{tabular}

$\mathrm{F}=$ Female; $\mathrm{M}=$ male. ${ }^{\mathrm{a}}$ Mean values \pm SEM and $\mathrm{p}$-values are given. Significant $\mathrm{p}$ values $(\mathrm{p}<0.05)$ are presented in italics. ${ }^{*}$ Two-sided t-test; ${ }^{\dagger} \chi^{2}$-test.

shows the baseline characteristics of moderately (BMI $<40 \mathrm{~kg} / \mathrm{m}^{2}$ ) and severely obese (BMI $\geq 40.0 \mathrm{~kg} / \mathrm{m}^{2}$ ) participants.

First, weight loss of the completers during the 1-year program was analyzed regardless of their initial BMI. At the beginning of the program ( $\left.\mathrm{T}_{0}\right)$, mean BMI was $41.8 \pm 0.5 \mathrm{~kg} / \mathrm{m}^{2}$. During the weight reduction phase, average weight loss was $15.6 \pm 0.3 \%$, resulting in a BMI of $35.3 \pm 0.4 \mathrm{~kg} / \mathrm{m}^{2}$ at $\mathrm{T}_{1}\left(\mathrm{~T}_{0}\right.$ vs. $\left.\mathrm{T}_{1} ; \mathrm{p}<0.001\right)$. During the subsequent weight maintenance period a further weight loss of $2.2 \pm 0.5 \%$ was achieved ( $\mathrm{T}_{1}$ vs. $\left.\mathrm{T}_{2} ; \mathrm{p}<0.001\right)$. Thus, participants achieved a total weight loss of $17.9 \pm 0.6 \%$ and a BMI of $34.3 \pm 0.4 \mathrm{~kg} / \mathrm{m}^{2}$ at $\mathrm{T}_{2}\left(\mathrm{~T}_{0} \mathrm{vs}\right.$. $\mathrm{T}_{2} ; \mathrm{p}<0.001$ ). BMI at $\mathrm{T}_{0}$ was not significantly different in male and female participants (male $42.7 \pm 0.9 \mathrm{~kg} / \mathrm{m}^{2}$, female $41.3 \pm 0.5 \mathrm{~kg} / \mathrm{m}^{2} ; \mathrm{p}=0.13$ ). However, male participants achieved greater weight loss than their female counterparts during the weight reduction phase (male $-17.4 \pm 0.5 \%$, female $-14.7 \pm 0.3 \% ; \mathrm{p}<0.001$ ), leading to a significant greater weight loss during the whole program (male $-20.5 \pm 1.0 \%$, female $-16.5 \pm 0.7 \%$; $<0.001$ ). Weight development during the weight maintenance phase was comparable in male and female participants (male $-3.1 \pm 0.8 \%$, female $-1.8 \pm 0.6 \%$; $=0.17$ ).

Next, BMI subclasses were analyzed (fig. $1 \mathrm{~A}$ ). At $\mathrm{T}_{0}, 31$ participants had a BMI of 30.0$34.9 \mathrm{~kg} / \mathrm{m}^{2}, 71$ a BMI of $35.0-39.9 \mathrm{~kg} / \mathrm{m}^{2}, 52$ a BMI of $40.0-44.9 \mathrm{~kg} / \mathrm{m}^{2}, 39$ a BMI of $45.0-49.9$ $\mathrm{kg} / \mathrm{m}^{2}$, and 24 a BMI $\geq 50.0 \mathrm{~kg} / \mathrm{m}^{2}$. Participants of all initial BMI classes achieved significant weight loss during the 1-year program. Mean weight reduction was $-16.3 \pm 1.0 \%$ for participants with an initial BMI of $30.0-34.9 \mathrm{~kg} / \mathrm{m}^{2}\left(\mathrm{~T}_{0}\right.$ vs. $\left.\mathrm{T}_{2} ; \mathrm{p}<0.001\right),-17.8 \pm 1.0 \%$ for participants with an initial BMI of $35.0-39.9 \mathrm{~kg} / \mathrm{m}^{2}$ ( $\mathrm{T}_{0}$ vs. $\mathrm{T}_{2} ; \mathrm{p}<0.001$ ), $-18.6 \pm 1.1 \%$ for participants with an initial BMI of $40.0-44.9 \mathrm{~kg} / \mathrm{m}^{2}\left(\mathrm{~T}_{0}\right.$ vs. $\left.\mathrm{T}_{2} ; \mathrm{p}<0.001\right),-18.2 \pm 1.4 \%$ for participants with an initial BMI of $45.0-49.9 \mathrm{~kg} / \mathrm{m}^{2}$ ( $\mathrm{T}_{0}$ vs. $\mathrm{T}_{2} ; \mathrm{p}<0.001$ ), and $-18.0 \pm 2.4 \%$ for participants with an initial BMI $\geq 50 \mathrm{~kg} / \mathrm{m}^{2}\left(\mathrm{~T}_{0}\right.$ vs. $\left.\mathrm{T}_{2} ; \mathrm{p}<0.001\right)$. Throughout all initial BMI 
Fig. 1. A Development of BMI from the beginning (T0) to the end (T2) of the program depicted for each individual according to the initial BMI class. B Changes in BMI classes during the 1-year weight reduction program (T0T2) shown for all initial BMI categories.
Winkler et al.: Effectiveness of a Low-Calorie Weight Loss Program in Moderately and Severely Obese Patients

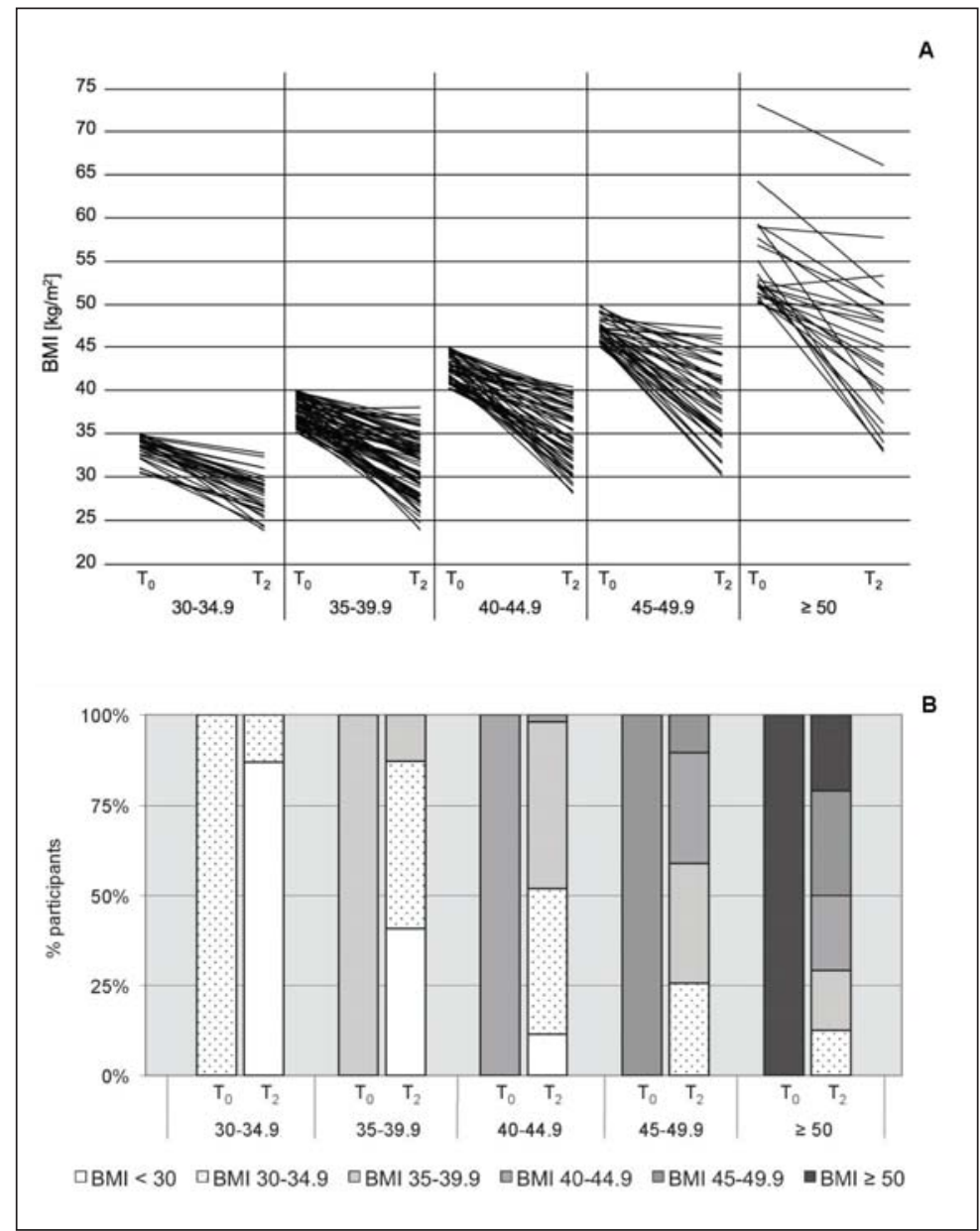

classes, a profound change of BMI categories was observed (fig. 1B). Only $12.9 \%$ of the participants with an initial BMI of $30-34.9 \mathrm{~kg} / \mathrm{m}^{2}$ remained in this BMI category, while $74.2 \%$ were classified as overweight and $12.9 \%$ as normal-weight at the end of the program. A comparable change was observed for participants of higher BMI categories (fig. 1B). For example, only $20.8 \%$ of the participants with an initial BMI $\geq 50.0 \mathrm{~kg} / \mathrm{m}^{2}$ remained in this category, while $29.2 \%$ reduced their weight to a BMI of $45.0-49.9 \mathrm{~kg} / \mathrm{m}^{2}, 20.8 \%$ to a BMI of $40.0-44.9$ $\mathrm{kg} / \mathrm{m}^{2}, 16.7 \%$ to a BMI of $35.0-39.9 \mathrm{~kg} / \mathrm{m}^{2}$, and $12.5 \%$ even achieved a BMI of $30.0-34.9$ $\mathrm{kg} / \mathrm{m}^{2}$ at the end of the program (fig. 1B).

In addition, we analyzed whether the program was as effective in severely obese (BMI $\geq$ $40.0 \mathrm{~kg} / \mathrm{m}^{2}$ ) as in moderately obese participants (BMI $<40 \mathrm{~kg} / \mathrm{m}^{2}$ ) (fig. 2). Overall weight loss during the whole program (moderately $-17.3 \pm 0.7 \%$, severely $-18.3 \pm 0.9 \% ; p=0.38$ ) and proportion of subjects losing more than $10 \%$ of their initial body weight (moderately $-82.4 \%$, severely -81.7\%; $\mathrm{p}=0.91$ ) did not significantly differ between both groups. Furthermore, development of weight reduction during the first phase of the program was comparable (moderately $-16.1 \pm 0.4 \%$, severely $-15.2 \pm 0.4 \%$; $\mathrm{p}=0.08$ ). Yet, during the weight maintenance phase severely obese participants lost significantly more additional weight compared to moderately obese participants (moderately $-1.2 \pm 0.6 \%$, severely $-3.1 \pm 0.7 \% ; p=0.04$ ). The same effects were observed for participants with a BMI $<35 \mathrm{~kg} / \mathrm{m}^{2}$ compared to those with a BMI $\geq 35 \mathrm{~kg} / \mathrm{m}^{2}(\mathrm{p}=0.03)$. Nevertheless, the percentage of subjects experiencing a weight regain of at least $5 \%$ during the weight maintenance phase was not significantly 
Fig. 2. Weight loss (in \%) of moderately obese (BMI $<40 \mathrm{~kg} / \mathrm{m} 2$ ) compared to severely obese participants (BMI $\geq 40 \mathrm{~kg} / \mathrm{m} 2$ ) during the 1-year program (T0-T2), the weight reduction (T0-T1) and the weight maintenance (T1-T2) phase. Error bars indicate SEM. *, $\mathrm{p}<0.05$.

Table 3. Multivariate logistic regression analysis assessing the independent effect of baseline BMI $\left(\mathrm{T}_{0}\right)$ on weight loss (\%) during the weight maintenance phase $\left(\mathrm{T}_{1}-\mathrm{T}_{2}\right)^{\mathrm{a}}$
Winkler et al.: Effectiveness of a Low-Calorie Weight Loss Program in Moderately and Severely Obese Patients

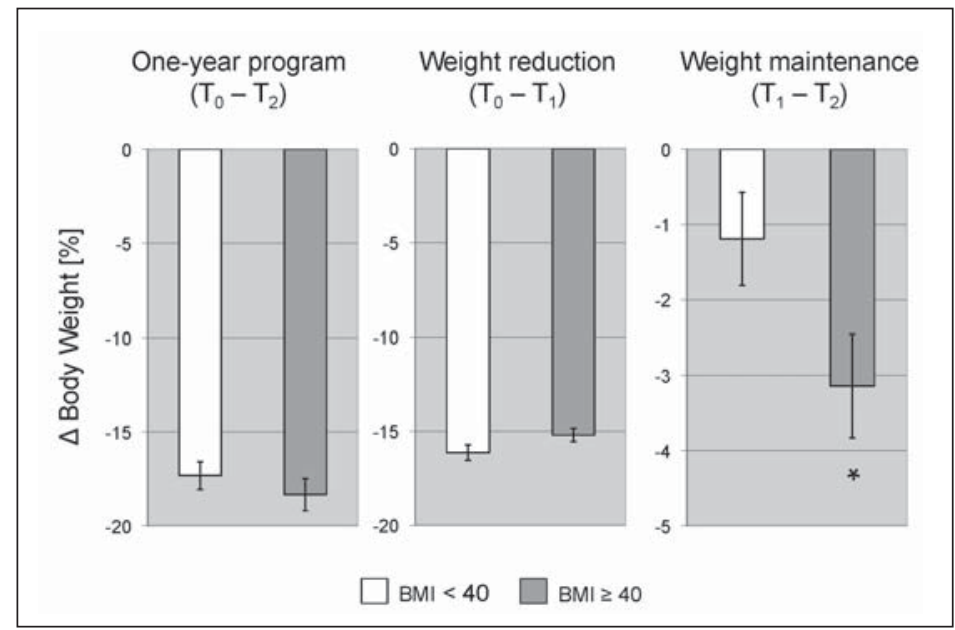

\begin{tabular}{llll}
\hline & Standard coefficient & Standard error & p value \\
\hline Sex & 0.890 & 1.174 & 0.45 \\
Age & -0.044 & 0.051 & 0.39 \\
Diabetes & 2.183 & 1.539 & 0.16 \\
Hypertension & 0.324 & 1.198 & 0.79 \\
BMI $\left(\mathrm{T}_{0}\right)$ & -0.199 & 0.090 & 0.03 \\
\hline
\end{tabular}

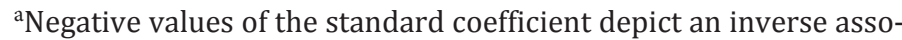
ciation with weight loss. Significant $p$ values $(p<0.05)$ are presented in italics.

different between both groups (moderately 16.7\%, severely 13.9\%; $\mathrm{p}=0.57$ ). Additionally, to exclude any influence of age, gender, diabetes, and hypertension on this additional weight loss, a multiple logistic regression model was performed (table 3). The analysis demonstrated an independent effect of the initial BMI on the additional weight loss during the weight maintenance phase of the program $(\mathrm{p}=0.03)$.

In addition to weight loss evaluation, lipid profiles were analyzed (fig. 3). Concentrations of total cholesterol, LDL cholesterol, HDL cholesterol and triacylglycerols were significantly improved during the 1-year program. Cholesterol was significantly reduced from $201 \pm 3$ $\mathrm{mg} / \mathrm{dl}$ at $\mathrm{T}_{0}$ to $192 \pm 3 \mathrm{mg} / \mathrm{dl}$ at $\mathrm{T}_{2}(\mathrm{p}<0.001$; fig. 3A). Levels of LDL cholesterol significantly improved from $122 \pm 2 \mathrm{mg} / \mathrm{dl}$ at $\mathrm{T}_{0}$ to $113 \pm 3 \mathrm{mg} / \mathrm{dl}$ at $\mathrm{T}_{2}(\mathrm{p}<0.01$; fig. 3B). Mean HDL cholesterol significantly increased under the intervention from $50 \pm 1 \mathrm{mg} / \mathrm{dl}$ at $\mathrm{T}_{0}$ up to $57 \pm 1$ $\mathrm{mg} / \mathrm{dl}$ at $\mathrm{T}_{2}(\mathrm{p}<0.001$; fig. $3 \mathrm{C})$. Additionally, triacylglycerols significantly decreased by more than $25 \%$ from $145 \pm 6 \mathrm{mg} / \mathrm{dl}$ at $\mathrm{T}_{0}$ to $105 \pm 5 \mathrm{mg} / \mathrm{dl}$ at $\mathrm{T}_{2}$ ( $\mathrm{p}<0.001$; fig. 3D). Analysis according to the initial BMI classes revealed that the improvement in lipid profiles was present throughout all BMI categories (fig. 3).

Furthermore, effects on blood glucose control were studied according to the participants' initial BMI (fig. 4, 5). At the end of the program mean fasting glucose was significantly lower compared to the levels at $\mathrm{T}_{0}\left(\mathrm{~T}_{0} 107 \pm 2 \mathrm{mg} / \mathrm{dl}_{,} \mathrm{T}_{2} 97 \pm 1 \mathrm{mg} / \mathrm{dl} ; \mathrm{p}<0.001\right)$. According to their fasting glucose, $16.1 \%$ of the participants were diagnosed with IFG and $18.4 \%$ with type 2 diabetes at the beginning of the program (fig. 4A). At the end of the program, the rate of IFG 
Winkler et al.: Effectiveness of a Low-Calorie Weight Loss Program in Moderately and Severely Obese Patients

A

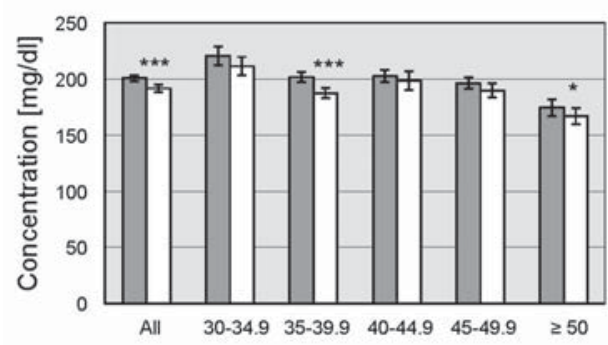

C

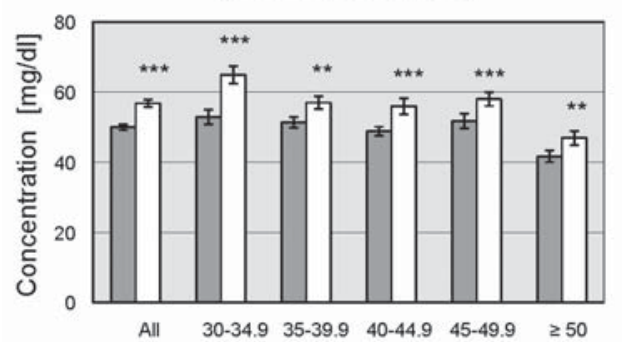

B

\section{LDL Cholesterol}

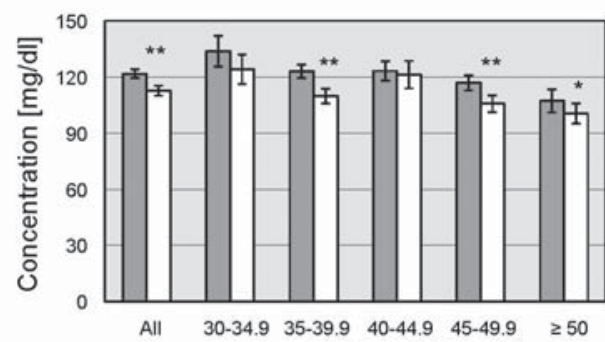

D

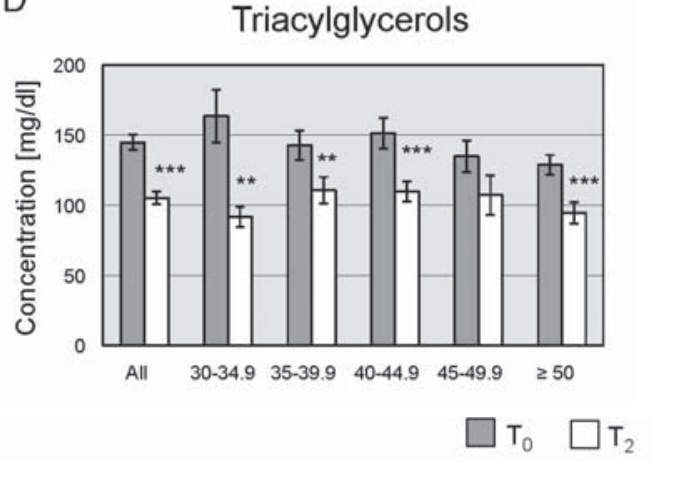

Fig. 3. Lipid metabolism depicted for all initial BMI classes comparing the lipid concentrations at the beginning (T0) and the end of the program (T2). A Total cholesterol levels (in mg/dl) B LDL cholesterol levels (in $\mathrm{mg} / \mathrm{dl}$ ) C HDL cholesterol levels (in mg/dl) D Triacylglycerol levels (in mg/dl). Error bars indicate SEM. *, $\mathrm{p}<0.05 ;{ }^{* *}, \mathrm{p}<0.01 ;{ }^{* * *}, \mathrm{p}<0.001$.

was reduced to $6.9 \%(\mathrm{p}<0.01)$ and the rate of type 2 diabetes to $6.3 \%(\mathrm{p}<0.001)$. Results from an OGTT were available in a subgroup of 91 patients. At $\mathrm{T}_{0}, 14.3 \%$ of these patients were diagnosed with IGT and $9.9 \%$ with type 2 diabetes. At the end of the program, only $5.5 \%$ of the participants had an IGT ( $p=0.18$ ) and only $2.2 \%$ had type 2 diabetes $(\mathrm{p}<0.001$; fig. $4 \mathrm{~B})$ according to the OGTT. This results in a diabetes conversion rate of $65.6 \%$ according to the fasting glucose values and $77.8 \%$ according to the results of the OGTT. To study insulin sensitivity, the HOMA-index was calculated. Mean HOMA-index significantly decreased from $7.1 \pm$ 0.6 at $\mathrm{T}_{0}$ to $3.4 \pm 0.2$ at $\mathrm{T}_{2}(\mathrm{p}<0.001$; fig. 5). Evaluation according to the initial BMI classes showed similar improvements throughout all BMI categories (fig. 4, 5).

Moreover, there was a trend towards an improved systolic blood pressure and a significant improvement of diastolic blood pressure during the program (140 $\pm 1 \mathrm{~mm} \mathrm{Hg} / 89 \pm 1$ mm Hg vs. $136 \pm 2$ mm Hg / $85 \pm 1$ mm Hg; RR systolic $p=0.05$, RR diastolic $p=0.03$ ).

\section{Discussion}

Our results demonstrate a comparable effectiveness of a 1-year medically supervised weight loss program in moderately and severely obese individuals. Throughout all initial BMI categories, a substantial decrease in BMI and an improvement of lipid and glucose metabolism were found. This underlines the benefit of such programs for obese patients regardless of their BMI category at baseline. 
Winkler et al.: Effectiveness of a Low-Calorie Weight Loss Program in Moderately and Severely Obese Patients

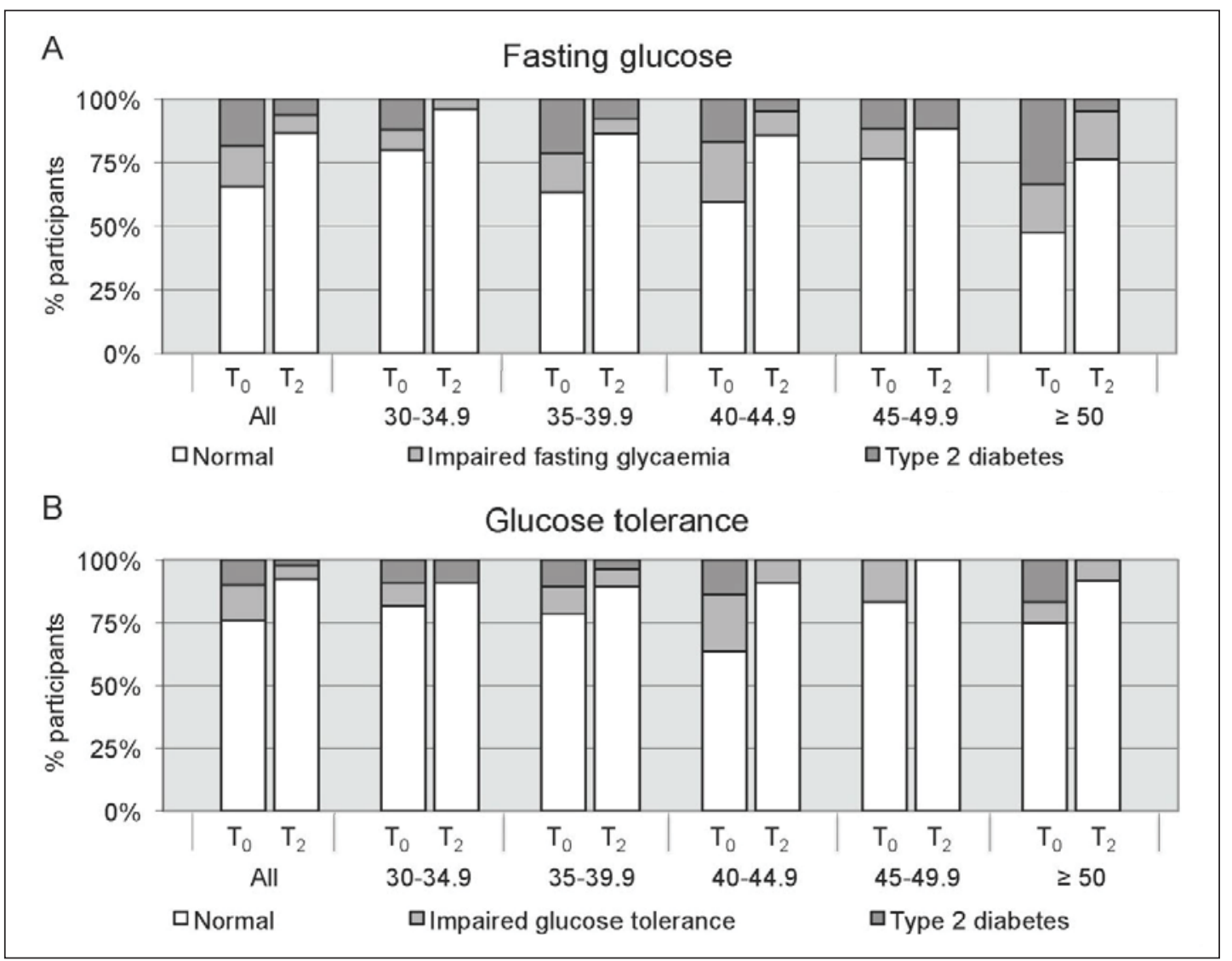

Fig. 4. A Participants of all initial BMI classes (in \%) diagnosed with type 2 diabetes or IFG based on their fasting glucose levels at the beginning (T0) and at the end (T2) of the program. B Participants of all initial BMI categories (in \%) diagnosed with type 2 diabetes or IGT based on the results of an OGTT at T0 and T2.

Fig. 5. HOMA index depicted for all initial BMI classes comparing indices at the beginning (T0) and at the end of the program (T2). Error bars indicate SEM. *, p $<0.05$; **, $\mathrm{p}<0.01 ; * * *, \mathrm{p}<0.001$.

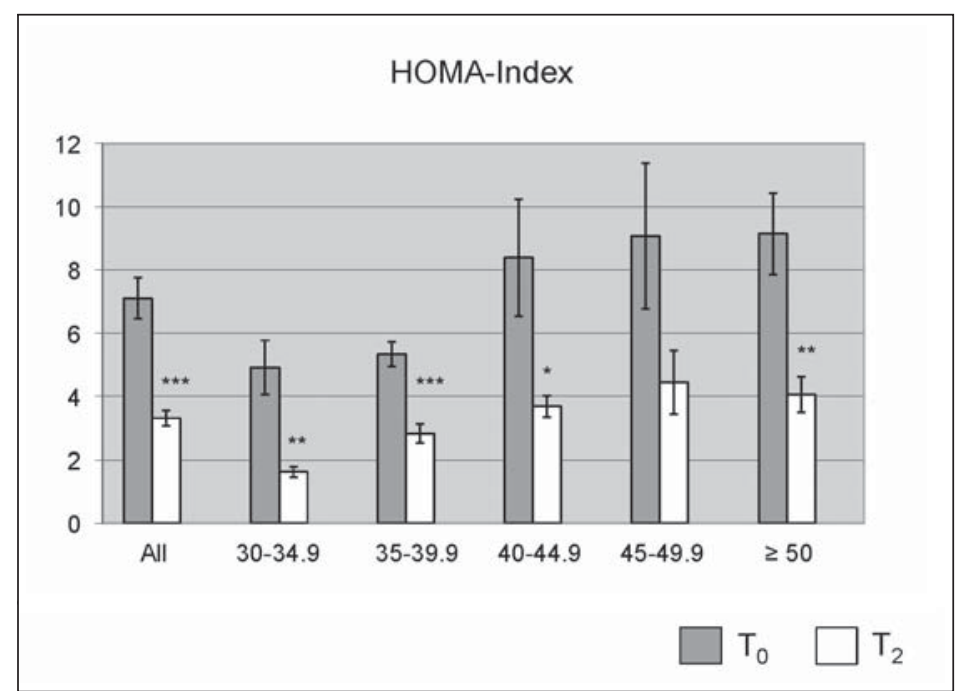


Winkler et al.: Effectiveness of a Low-Calorie Weight Loss Program in Moderately and Severely Obese Patients

In contrast to previously assumed limitations of weight loss programs in severe obesity [8], we found similar weight loss in moderately and severely obese participants during this 1 -year program. Successful weight loss, defined as weight reduction greater than $10 \%$ of body weight $[13,14]$, was achieved by over $80 \%$ of the severely obese participants, with the average overall weight loss being $18.3 \%$. This is comparable to the weight loss achieved by the moderately obese participants in our study and to the average weight loss depicted in a recently published first evaluation of this program [11].

We suggest that the multidisciplinary medically supervised approach of the analyzed weight loss program is successful not only in moderately obese but also in severely and super obese individuals. The effectiveness is underlined by the fact that a significant weight loss was achieved not only in the weight reduction phase but also in the weight maintenance phase. It has previously been shown that particularly weight maintenance, which determines the longterm success of a weight reduction intervention, is difficult to accomplish [13, 15-17]. Remarkably, we found that severely obese participants realized greater weight loss than moderately obese participants during this phase, which emphasizes that severely obese patients achieved sustainable weight loss for at least 1 year. We assume that an improvement of eating habits is facilitated by individualized nutrition counseling and psychological support during the program. An interdisciplinary and individualized approach appreciating psychological aspects (e.g. addictive-like overeating) has previously been suggested to improve weight stabilization [17]. These aspects, however, are often unattended in bariatric surgery $[8,18]$, which possibly contributes to the fact that significant weight regain may also occur in severely and super obese patients that have undergone bariatric surgery $[8,18,19]$.

Our results concerning short-term weight maintenance are very promising. Formula diet-based weight loss programs show an increased effectiveness compared to intensive lifestyle intervention programs without formula diet approaches [20, 21]. In the 'Look AHEAD Trial' patients with diabetes were randomized to an intensive lifestyle intervention or diabetes support and education only group. In comparison to the OPTIFAST ${ }^{\circledR} 52$ program the intervention period lasted over 4 years. With respect to weight loss, this approach resulted in a weight reduction of about $4-5 \%$ and was therefore significantly less effective than the formula diet-based program. Interestingly, the authors detected no differences in weight loss between severely obese participants (BMI class III), which lost $4.9 \pm 8.5 \%$, and participants with BMI of class I, which lost $4.8 \pm 7.2 \%$ of their initial body weight [20]. Furthermore, the rate of partial or complete diabetes remission $(11.5 \%)$ was lower compared to our results (65.6\%). This might derive from the lower extend of body weight reduction, which might be the driving force in diabetes remission [22]. Our data indicate that a low calorie-based intensive lifestyle intervention program is more effective than an intensive lifestyle intervention program after a time of 12 months.

However, preliminary data on the long-term success of the OPTIFAST ${ }^{\circledR} 52$ program are rather disappointing and show that only $30 \%$ of the patients realize successful weight maintenance over a time period of 3 years [11]. After 3 years the advantage seen after 12 months seems to disappear with a weight reduction of only $4.2 \%$ compared to the initial body weight. This is comparable to the 4-year results of the 'Look AHEAD Trial'. However, in this trial patients were individually consulted on monthly bases during years $2-4$ and were offered a variety of group classes.

At present, it is not clear whether the disappointing long-term results of non-surgical programs are unavoidable or just a result of the missing long-term follow-up support after an initially successful intervention. Therefore, we presume that weight stabilization after such programs should be augmented by medically supervised long-term follow-up. However, a regular long-term treatment after attendance of such programs is not provided at the moment. 
Winkler et al.: Effectiveness of a Low-Calorie Weight Loss Program in Moderately and Severely Obese Patients

Besides weight reduction, positive effects on the lipid and glucose metabolism were found. Moreover, the typical obesity-related 'atherogenic lipid triad', defined as high triglyceride levels, low HDL cholesterol levels, and high levels of LDL cholesterol particles, was improved in all BMI classes during the program. Additionally, a diabetes conversion rate of over $65 \%$ was achieved regarding patients with overt type 2 diabetes at baseline. By counteracting cardiovascular risk factors the benefits of low-calorie weight loss programs go beyond the success of weight loss [23]. Our results underline that medically supervised programs are a suitable approach in the treatment of type 2 diabetes, especially if bariatric surgery is refused by the patient or not feasible [24]. However, endpoint studies clearly demonstrating a favorable outcome are still missing.

There are some limitations of our study. An attrition rate of $30.2 \%$ is quite high which might have distorted our analyses. It is mainly caused by the expensive fees, which have to be paid on a monthly basis as long as the participants stay in the program and add up to total costs of EUR 3,000.- for the whole program. 52 participants declared financial problems. Furthermore, 22 participants claimed business-related reasons, e.g. movement due to a new job, newly developed unemployment or changed working schedules. Four female participants became pregnant during the program and 16 left without stating any statement. Especially the high costs of the program are likely to influence the outcome of our study since mainly wealthy people can afford to participate. Further limitations derive from the fact that two thirds of the participants were female. Yet, female participants achieved less weight reduction during the 1-year program than male participants, which may be due to the fact that the low-calorie diet meant greater caloric restriction for men than for women $[11,25]$. Furthermore, our results concerning changes in blood pressure only have limited validity because prescribed antihypertensive medication and lipid-lowering agents could frequently be reduced during the 1-year program, which was not documented in the charts.

Our study is the first, which clearly demonstrates that not only moderately but also severely obese patients profit from non-surgical weight loss approaches in regard to weight reduction, treatment of diabetes, and improvements of lipid profiles. This is highly important because medical treatment approaches are often more accepted [11], less invasive [26, 27], and feasible for patients with special risks for bariatric surgery [28]. However, long-term success after such programs remains a major issue. Conclusively, we assume that medically supervised follow-up counseling over several years may significantly improve the long-term success of weight loss programs, particularly in severely obese patients.

\section{Acknowledgments}

This work was supported by a grant of EFSD (CRG 2012/13; GR, CW) and of ERC (AdipoDif CW).

\section{Disclosure Statement}

The authors have nothing to disclose. 
Winkler et al.: Effectiveness of a Low-Calorie Weight Loss Program in Moderately and Severely Obese Patients

\section{References}

1 James PT, Leach R, Kalamara E, Shayeghi M: The worldwide obesity epidemic. Obes Res 2001;9(suppl 4):228S233S.

2 World Health Organization: Obesity: preventing and managing the global epidemic. Report of a WHO consultation. World Health Organ Tech Rep Ser 2000;894:i-xii, 1-253.

-3 Curbing the obesity epidemic. Lancet 2006;367:1549.

4 World Health Organization: Obesity and Overweight.Fact sheet $\mathrm{N}^{\circ} 311.2011$. www.who.int/mediacentre/factsheets/fs311/en/.

5 Sturm R: Increases in morbid obesity in the USA: 2000-2005. Public Health 2007;121:492-496.

6 Hubert HB, Feinleib M, McNamara PM, Castelli WP: Obesity as an independent risk factor for cardiovascular disease: a 26-year follow-up of participants in the Framingham Heart Study. Circulation 1983;67:968-977.

7 Tsai AG, Wadden TA: Systematic review: an evaluation of major commercial weight loss programs in the United States. Ann Intern Med 2005;142:56-66.

-8 Herpertz S, Kielmann R, Wolf AM: Psychosocial aspects of obesity surgery (in German). Aktuel Ernahrungsmed 2002;27:149-156.

-9 Sarwer DB, Wadden TA, Fabricatore AN: Psychosocial and behavioral aspects of bariatric surgery. Obes Res 2005;13:639-648.

10 Buchwald H, Avidor Y, Braunwald E, Jensen MD, Pories W, Fahrbach K, Schoelles K: Bariatric surgery: a systematic review and meta-analysis. JAMA 2004;292:1724-1737.

-11 Bischoff SC, Damms-Machado A, Betz C, Herpertz S, Legenbauer T, Löw T, Wechsler JG, Bischoff G, Austel A, Ellrott T: Multicenter evaluation of an interdisciplinary 52-week weight loss program for obesity with regard to body weight, comorbidities and quality of life-a prospective study. Int J Obes (Lond) 2012;36:614-624.

12 World Health Organization: Definition and Diagnosis of Diabetes Mellitus and Intermediate Hyperglycaemia. 2006. www.who.int/diabetes/publications/Definition\%20and\%20diagnosis\%20of\%20diabetes_new.pdf.

13 Wing RR, Phelan S: Long-term weight loss maintenance. Am J Clin Nutr 200582(1 suppl):222S-225S.

14 Wing RR, Hill JO: Successful weight loss maintenance. Annu Rev Nutr 2001;21:323-341.

15 Woehning A, Schultz JH, Roeder E, Moeltner A, Isermann B, Nawroth PP, Wolfrum C, Rudofsky G: The A-allele of the common FTO gene variant rs9939609 complicates weight maintenance in severe obese patients. Int J Obes (Lond) 2013;37:135-139.

16 Gage D: Weight loss/maintenance as an effective tool for controlling type 2 diabetes: novel methodology to sustain weight reduction. Diabetes Metab Res Rev 2012;28:214-218.

-17 Winkler JK, Woehning A, Schultz JH, Brune M, Beaton N, Challa TD, Minkova S, Roeder E, Nawroth PP, Friederich HC, Wolfrum C, Rudofsky G: TaqIA polymorphism in dopamine D2 receptor gene complicates weight maintenance in younger obese patients. Nutrition 2012;28:996-1001.

18 Hsu LK, Benotti PN, Dwyer J, Roberts SB, Saltzman E, Shikora S, Rolls BJ, Rand W: Nonsurgical factors that influence the outcome of bariatric surgery: a review. Psychosom Med 1998;60:338-346.

19 Christou NV, Look D, Maclean LD: Weight gain after short- and long-limb gastric bypass in patients followed for longer than 10 years. Ann Surg 2006;244:734-740.

-20 Unick JL, Beavers D, Bond DS, Clark JM, Jakicic JM, Kitabchi AE, Knowler WC, Wadden TA, Wagenknecht LE, Wing RR; Look AHEAD Research Group: The long-term effectiveness of a lifestyle intervention in severely obese individuals. Am J Med 2013;126(3):236-242, 242.e1-2.

-21 Gregg EW, Chen H, Wagenknecht LE, Clark JM, Delahanty LM, Bantle J, Pownall HJ, Johnson KC, Safford MM, Kitabchi AE, Pi-Sunyer FX, Wing RR, Bertoni AG; Look AHEAD Research Group: Association of an intensive lifestyle intervention with remission of type 2 diabetes. JAMA 2012;308:2489-2496.

-22 Robert M, Ferrand-Gaillard C, Disse E, Espalieu P, Simon C, Laville M, Gouillat C, Thivolet C: Predictive factors of type 2 diabetes remission 1 year after bariatric surgery: impact of surgical techniques. Obes Surg 2013;23: 770-775.

-23 Martins C, Strømmen M, Stavne OA, Nossum R, Mårvik R, Kulseng B: Bariatric surgery versus lifestyle interventions for morbid obesity - changes in body weight, risk factors and comorbidities at 1 year. Obes Surg 2011;21:841-849.

24 Mingrone G, Panunzi S, De Gaetano A, Guidone C, Iaconelli A, Leccesi L, Nanni G, Pomp A, Castagneto M, Ghirlanda G, Rubino F: Bariatric surgery versus conventional medical therapy for type 2 diabetes. N Engl J Med 2012;366:1577-1585.

-25 Tsai AG, Wadden TA: The evolution of very-low-calorie diets: an update and meta-analysis. Obesity (Silver Spring) 2006;14:1283-1293.

26 Herron DM, Bloomberg R: Complications of bariatric surgery. Minerva Chir 2006;61:125-139.

27 Lee CW, Kelly JJ, Wassef WY: Complications of bariatric surgery. Curr Opin Gastroenterol 2007;23:636-643.

28 Pories WJ: Bariatric surgery: risks and rewards. J Clin Endocrinol Metab 2008;93(11 suppl 1):S89-96. 